\title{
Terminalidade de vida: bioética e humanização em saúde
}

\section{Completion of life: bioethics and humanization in health}

\author{
Mariana O. Marengo'1, Daniela A. Flávio², Ricardo Henrique Alves da Silva ${ }^{3}$
}

\begin{abstract}
RESUMO
A visão dos profissionais de saúde frente à terminalidade da vida é uma das realidades mais difíceis com as quais estes se deparam, pois, apesar dos melhores esforços, alguns pacientes virão a óbito. 0 objetivo do presente estudo é identificar e descrever, por meio da literatura científica, os aspectos da promoção de saúde e da Bioética, no que diz respeito à humanização do atendimento aos sujeitos em terminalidade de vida, frente aos familiares e profissionais de saúde envolvidos. A metodologia baseouse em uma revisão de literatura através de pesquisa e seleção de textos a partir de bases de dados, proporcionando o conhecimento acerca dos diferentes conceitos utilizados na humanização dos profissionais de saúde com relação à terminalidade de vida e questões bioéticas, a fim de buscar suprir as grandes dificuldades que os profissionais de saúde têm em lidar com os doentes terminais e como devem ser tratados, uma vez que o bem estar físico e emocional deve ser o foco das atenções.
\end{abstract}

Palavras-chave: Bioética. Humanização da Assistência. Doente Terminal. Cuidados Paliativos.

\section{Introdução}

Segundo Gutierrez $(2001)^{1}$, a terminalidade de vida é quando se esgotam as possibilidades de resgate das condições de saúde e a possibilidade de morte próxima parece inevitável e previsível. O indivíduo se torna "irrecuperável" e caminha para a morte, sem que se consiga reverter este caminhar.

Admitir que os recursos para o resgate de uma cura se esgotaram e que o sujeito se encaminha para o fim da vida, não significa que não há mais o que fazer. Ao contrário, abre-se uma ampla gama de condutas que podem ser oferecidas, tanto ao sujeito que necessita de cuidados quanto seus familiares, visando, agora, o alívio da dor, a diminuição do desconforto, mas, sobretudo, a possibilidade de situar-se frente ao momento do fim da vida, acompanhados por alguém que possa ouvi-los e dar suporte. ${ }^{2}$

Desta forma, estabelece-se uma nova perspectiva de trabalho, multidisciplinar, denominada humanização que responde pela convivialidade, solidariedade, irmandade, amor e respeito, ou seja, corresponde
1. Graduação em Enfermagem pela Universidade Paulista.

2. Graduação em Enfermagem pela Universidade Paulista.

3. Docente. Odontologia Legal, Faculdade de Odontologia de Ribeirão Preto da Universidade de São Paulo.
Correspondência:

Prof. Dr. Ricardo Henrique Alves da Silva Faculdade de Odontologia de Ribeirão Preto - USP Departamento de Clínica Infantil, Odontologia Preventiva e

Social

Avenida do Café, s/n, Bairro Monte Alegre 14040-904 - Ribeirão Preto-SP ricardohenrique@usp.br

Artigo recebido em 10/02/2009 Aprovado em 31/08/2009 
ao cuidado, adotando uma abordagem humanista e integrada para o tratamento de seres humanos sem possibilidade de cura, reduzindo os sintomas e aumentando a qualidade de vida, a fim de criar um espaço favorecedor de despedidas, de preparo para a separação e de um pensar na vida daqueles que sobreviverão. $^{2}$

Nesse sentido, o sofrimento humano, as percepções de dor ou de prazer no corpo, para serem humanizadas, precisam tanto que as palavras com que o sujeito se expressa sejam reconhecidas pelo outro, quanto esse sujeito precisa ouvir do outro, palavras de seu reconhecimento. ${ }^{3}$ De acordo com Waldow (2006), ocorrem distúrbios sérios de comunicação entre pessoas gravemente enfermas e seus familiares, com sentimentos intensos que não são expressos.

Como a sociedade atual cala o luto, cabe aos profissionais de saúde, engajados no processo de rehumanização da morte, abrir espaço para a expressão da dor e sofrimento, numa atmosfera acolhedora.

A humanização nos Cuidados Paliativos tem como base argumentativa fundamental a busca incessante pela dignidade humana; repertório que deveria acompanhar a todos desde o mais remoto sinal de vida até a morte, realçando a imprescindível incorporação dos aspectos subjetivos ao processo de adoecimento, aliás, a sua mais primorosa contribuição e maior desafio aos profissionais de saúde, reside na convocação à transformação do conhecimento científico em verdade e sabedoria. ${ }^{5}$

Desta forma, o presente estudo, compreendendo a morte enquanto parte integrante da vida, visa identificar e descrever, por meio da literatura científica, os aspectos da promoção de saúde, no que diz respeito à humanização do atendimento aos sujeitos em terminalidade de vida, frente aos familiares e profissionais de saúde envolvidos.

\section{Material e Métodos}

Foi realizado um levantamento bibliográfico dos últimos quinze anos nos sites de busca científicos a seguir descritos: Bireme (Biblioteca Virtual em Saúde, serviço especializado da Organização Pan-Americana de Saúde), especificamente nas bases de dados: (a) Lilacs (Literatura Latino-Americana e do Caribe em Ciências da Saúde): compreende a literatura relativa às ciências da saúde, publicada nos países da América Latina e Caribe, a partir de 1982, composta por revistas, teses, capítulos de teses, livros, capítulos de livros, anais de congressos ou conferências, relatórios técnico-científicos e publicações governamentais; (b) Scielo (Scientific Electronic Library Online): publicação eletrônica de periódicos científicos que disponibiliza de modo gratuito, os textos completos de mais de 290 revistas científicas do Brasil, Chile, Cuba, Espanha, Venezuela e outros países da América Latina.

Foram utilizados como descritores em português: bioética, humanização, doente terminal, cuidado paliativos. E como descritores em inglês: bioethics, humanization, terminal patient, palliative care.

A revisão da literatura realizada foi do tipo sistemática, sendo adotados os seguintes critérios de inclusão: 1) ter sido publicado no período de 1993 a 2007; 2) o assunto descrito ser pertinente ao objeto de estudo; 3) objetivo claro e ser fiel ao estudo realizado; 4) ser baseado na literatura anterior; 5) conclusão de acordo com o encontrado.

Os trabalhos foram selecionados de acordo com sua compatibilidade no que se refere à estrutura e à metodologia. Os artigos incluídos nesta revisão de literatura foram selecionados após a adoção dos critérios de inclusão citados, sendo que após a análise metodológica, foram utilizados $n=47$ trabalhos, que foram discutidos em diferentes tópicos, agrupados a partir da análise dos textos selecionados.

A discussão apresenta-se agregada aos resultados, na forma de revisão de literatura, pois se trata de um estudo de revisão qualitativo descritivo.

\section{Revisão de Literatura}

\section{Humanização}

O desafio da humanização é criar para os seres humanos oportunidades de existir e viver dignamente. Na atualidade, esquece-se de que, se as coisas têm preço e podem ser trocadas, alteradas ou comercializadas, as pessoas têm dignidade e clamam por respeito. A manipulação se faz presente sutilmente e rouba aquilo que é mais precioso à vida do ser humano: sua dignidade. ${ }^{6}$

O contato direto com seres humanos, em estado de saúde ou doença, coloca o profissional de saúde diante de sua própria vida, dos próprios conflitos e frustrações e, se o profissional não tomar cuidado com esses fenômenos, correrá o risco de, ao entrar em contato com outros seres humanos, utilizar o distanciamento como mecanismo de defesa, devido a ten- 
sões provenientes de várias fontes: contato frequente com a dor e o sofrimento; receio de cometer erros; relações com pacientes difíceis. ${ }^{7}$

A busca da perfeição seria justamente a de uma natureza humana mais forte que o presente, sendo relevante entender tal "perfeição" não em sentido essencialista, mas correspondendo à passagem de uma perfeição menor a uma perfeição maior, na direção de um maior conhecimento da relação da mente com a natureza. Seria este conhecimento, o da real necessidade da natureza humana, levando adiante dos equívocos da imaginação, que conduziria à ação correta e à felicidade, ou seja, ao "bem supremo". ${ }^{8}$

O processo de humanização nas instituições hospitalares pressupõe, em primeiro lugar, a compreensão do significado da vida do ser humano, o que não é uma tarefa fácil, ao envolver diversos fatores, além de princípios éticos, aspectos culturais, econômicos, sociais e educacionais. Afora isso, a maneira de cuidar nem sempre admite resposta adequada e produtiva. Entender a vida e decifrá-la é tarefa das mais difíceis, uma vez que a humanização precisa ser sentida e percebida. ${ }^{9}$

O conceito de humanização alinha-se a uma série de propostas de revisão e de mudança nas relações entre equipes, profissionais, gestores e usuários dos serviços de saúde, abrangendo o emprego das tecnologias de escuta, acolhimento, diálogo e negociação para a produção e gestão do cuidado. ${ }^{10} \mathrm{E}$, diante do cenário de terminalidade de vida, muitas vezes gerador de sofrimento, é possível programar uma política de assistência e cuidado que honre a dignidade do ser humano doente. ${ }^{11}$

No humanismo situam-se numerosos aspectos filosóficos, sociais, econômicos, políticos, antropológicos e psicológicos, e cada um pode ser tratado diferentemente, sendo o ponto essencial a necessidade de avaliar as relações dos seres humanos entre si e com o meio social. ${ }^{12}$

O debate que envolve a humanização aposta em processos relacionais re-significados, tendo como horizonte uma maior reciprocidade entre as expectativas de vida, de felicidade e a produção dos cuidados. O processo terapêutico, neste sentido, ganha em validade cultural e afetiva, ampliando sua legitimidade. ${ }^{13}$

De acordo com Lepargneur $(2003)^{14}$, humanizar é saber promover o bem comum acima da suscetibilidade individual ou das conveniências de um pequeno grupo. Entretanto, humanizar é estar sempre se colo- cando no lugar do paciente, é realizar para o próximo aquilo que gostaria de receber.

O cuidar humanizado implica, por parte do cuidador, a compreensão do significado da vida, a capacidade de perceber e compreender a si mesmo e ao outro. Humanizar o cuidar é dar qualidade a relação profissional da saúde-usuário so serviço, ou seja, acolher as angústias do ser humano diante da fragilidade de corpo, mente e espírito ${ }^{6}$, e não se pode humanizar o ambiente hospitalar sem referência ao humano e não se pode falar do humano sem referência à Ética. ${ }^{15}$

\section{Terminalidade de vida}

No processo da terminalidade deve-se levar em conta não a quantidade de vida que resta à pessoa, mas sim a qualidade de vida. ${ }^{16}$ Uma das realidades mais difíceis com as quais os profissionais da saúde se deparam é que, apesar dos melhores esforços, alguns indivíduos morrerão.

E, embora não seja possível alterar esse fato, é possível ter um efeito significativo e duradouro sobre a maneira pela qual o sujeito vive até o momento da morte, a maneira pela qual a morte acontece e as memórias que ficam da morte para a família. A educação, a prática clínica e a pesquisa sobre o cuidado em fase terminal estão evoluindo, e a necessidade de preparar profissionais da saúde para o cuidado ao sujeito em fase terminal surge como uma prioridade. ${ }^{17}$

De acordo com estudo realizado por Siqueira $(2003)^{18}$, das 126 escolas de Medicina norte-americanas existentes, apenas cinco oferecem ensinamentos sobre a terminalidade da vida; maior ainda é a desatenção ao tema nos 7.048 programas de residência médica, já que apenas 26 apresentam o assunto em reuniões científicas.

Saloum e Boemer (1999) ${ }^{19}$ relatam grandes transformações na forma do ser humano entender e lidar com a morte na sociedade ocidental, principalmente ao compreender que de acontecimentos esperados, naturais, compartilhados, a morte passou a ser enfocada como um evento que ocorre, predominantemente, no contexto hospitalar, remetendo a um morrer solitário, institucionalizado.

Os avanços tecnológicos na Medicina têm permitido salvar a vida de doentes críticos, desde que haja alguma potencialidade de reversibilidade. Entretanto, naqueles sem possibilidade de recuperação, a utilização de medidas curativas, além de onerosas e sem benefícios, acabam causando apenas dor e sofrimento. ${ }^{20}$ 
Neste caso, a Medicina tecnológica, ao prolongar a vida, torna o processo da morte lento e sofrido. O grande desafio que se impõe é definir quem se beneficiará com todo suporte tecnológico, ou seja, distinguir quem tem uma situação potencialmente curável daquele em que, pela irreversibilidade do processo, as medidas terapêuticas são inócuas. ${ }^{20}$

A obstinação terapêutica leva até as últimas consequências a tentativa de afastar a morte e, nessa tentativa, o sujeito não morre mais na sua hora, mas naquela da equipe de saúde. ${ }^{21}$

As Unidades de Terapia Intensiva (UTI) cumprem a função de fornecer o máximo da ciência médica possível na busca da cura das doenças e prolongamento da vida, mas, no âmbito emocional, afasta o médico do vínculo com pessoas em estados graves ou terminais. ${ }^{22}$

Desta forma, a Medicina pratica sofisticada tecnologia e subestima o confronto do enfermo terminal, impondo-lhe longa e sofrida agonia, sendo necessário o resgate de sentimentos como compreensão, solidariedade e compaixão sem o que se torna uma ciência fria que não contempla a dignidade do ser humano. ${ }^{18}$

\section{O contexto de morte e o morrer}

Nas últimas três décadas, cresceu o interesse pela fase terminal, com ênfase sobre os ambientes em que ocorre a morte, sobre as tecnologias empregadas para sustentar a vida e os desafios de tentar melhorar os cuidados em fase terminal. ${ }^{23}$

Estar enfermo é perder a integridade da saúde e o objetivo fundamental da Medicina é tratar os enfermos buscando restabelecer a integridade perdida, ou seja, a busca pela cura ocorre quando a saúde, entendida como o bem-estar biológico, psicossocial e espiritual, é plenamente restabelecida. ${ }^{6}$

Cuidar do atendimento espiritual dos pacientes é expandir-se na dimensão existencial do ser humano. Os profissionais têm a responsabilidade de incluí-la no mesmo grau de importância das técnicas de intervenção, pois como informa Mauksch (1975)24: "morrer é uma experiência total e na hora de morrer o órgão afetado deixa de ser o item básico".

Hoje se morre muito mais no hospital; é uma morte escondida das pessoas e isolada dos familiares, no entanto, a morte é a característica mais humana, pois o ser humano é o único animal que sabe que vai morrer. $^{25}$

No Brasil, se fala muito mais dos mortos do que da morte, o que implica em uma contradição, uma vez que falar dos mortos já é uma forma sutil e disfarçada de negar a morte, fazendo prolongar a memória do morto, onde a morte é concebida como uma passagem de um mundo a outro, uma metáfora de subida ou descida. ${ }^{26}$

No percurso final da vida, diante da inexorabilidade da morte, ainda surge a necessidade da presença solidária do profissional, acolhedor e disponível, pois os sujeitos enfermos estão vivos na cena da morte que já não poder ser evitada e, na proposta de Trein $(2002)^{27}$, "se não há solução para a morte do homem, talvez uma solução seja não deixar que as pessoas morram de solidão".

Dessa forma, ainda que a boa morte ou a morte digna inclua, como aponta Franco $(2002)^{28}$, características como ausência de dor, uso imaginativo de recursos sensoriais, estar rodeado pelas pessoas amadas, ser preparado para a morte, há que se perguntar o que é uma boa morte e uma má morte.

\section{Tecnologia e cuidados em fase terminal: aspetos éticos e bioéticos}

Embora os avanços tecnológicos nos cuidados de saúde tenham se ampliado e melhorado a qualidade de vida para muitos, a capacidade dos aparelhos em prolongar a vida, além do ponto em que alguns considerariam como significativo, suscita questões éticas inquietantes como: qualidade de vida, prolongamento do processo de morrer, adequação do alívio da dor, controle dos sintomas e alocações de recursos escassos. ${ }^{23}$

A principal questão ética que surge em relação ao uso de aparelhos para estender a vida é: Como podemos prolongar a vida por meio de determinada intervenção? É isso que devemos seguir necessariamente ? $^{23}$

Se é a vida, como valor absoluto, que deve ser mantida, nada poderá ser feito para a sua abreviação, e deve se evitar a morte a todo custo. Foi o desenvolvimento da tecnologia que favoreceu a manutenção e prolongamento da vida, e então se pergunta: até quando investir em tratamentos e quando interrompê-los ? $^{29}$

Assim, a Bioética é um ramo da Ética que enfoca questões referentes à vida humana e, consequentemente, à morte, propondo questões relativas às mais variadas situações, inclusive referente ao processo de morrer com dignidade. ${ }^{30}$

Segundo Barchifontaine (2007) ${ }^{31}$, Bioética é a ética da vida, da saúde e do meio-ambiente, com o 
papel de ampliar os horizontes, recolocando o paciente dentro de um contexto, que não é somente o hospital e a família, mas sim a sociedade como um todo, e que se desenvolve através de um diálogo transdisciplinar, transprofissional e transcultural, tendo, por finalidade, o resgate da dignidade da pessoa humana, com ênfase na qualidade de vida.

De acordo com Torres (2003) ${ }^{32}$, a Bioética propõe como princípios básicos a Justiça, a Autonomia, a Beneficência e a Não-Maleficência, e estes princípios se tornaram a base da ética profissional na área da saúde. O respeito pela pessoa, à sua liberdade e dignidade, é fundamental, portanto, a decisão deve ser respeitada, o que não exclui a necessidade de toda informação sobre as implicações, para que a decisão seja tomada com liberdade e, assim, garantida a dignidade da pessoa.

Com o progresso da Medicina, a adoção de terapias de suporte de vida, no passado nem imaginável, tem dificultado cada vez mais a definição dos limites terapêuticos nos cuidados intensivos, contrapondo os princípios éticos da beneficência e da não-maleficência. $^{33}$

O conhecimento biológico e as destrezas tecnológicas tornaram o morrer mais problemático, fonte de complicados dilemas éticos e escolhas difíceis, geradoras de angústia, ambivalência e incerteza e, desta forma, a Bioética deve ajudar o profissional a repensar o seu papel dentro da saúde, ${ }^{17}$ embasado na Constituição Federal (1988) ${ }^{34}$, em seu artigo 196: "A saúde é direito de todos e dever do Estado, garantindo mediante políticas sociais e econômicas que visem á redução do risco de doença e de outros agravos e ao acesso universal e igualitário ás ações e serviços para sua promoção, proteção e recuperação".

\section{Atitudes dos profissionais de saúde diante da morte}

Na sociedade brasileira, a morte é tratada como um tema interditado, o que traduz toda uma forma de pensar e sentir a morte, e se apresenta com um sentido que parece ser absoluto e definitivo. Assim sendo, a morte é representada pelo pavor e pela necessidade imperativa e quase ritualizada da negação. ${ }^{35}$

Segundo Zoboli (2007) $)^{36}$, em alguns casos, essa relação profissional/paciente pode acabar se tornando quase de maternalismo/paternalismo. E os profissionais de saúde respondem a esse desafio muitas vezes com ansiedade e medo, sendo a solução uma formação apropriada sobre o assunto, mas a maioria dos programas de treinamento com frequência aborda esta realidade inadequadamente, existindo a necessidade de uma maior humanização do homem frente à sua vida e a dos outros. ${ }^{25}$

Cabe aos profissionais da saúde olhar para além das instituições, ampliar a noção do cuidado restrito a quatro paredes, enfim, tentar compreender as condições multifatoriais do processo saúde-doença. ${ }^{9}$

Talvez o remédio mais eficaz em termos de cura seja a qualidade do relacionamento mantido entre o sujeito enfermo e seus cuidadores, assim como a sua família. ${ }^{37}$ A qualidade curadora da relação terapêutica pode facilmente ser enfraquecida ou ameaçada quando reações emocionais (negação, raiva, culpa e medo) sentidas pelos enfermos, famílias ou cuidadores não são adequadamente trabalhadas. ${ }^{37}$

Pode-se perceber que os profissionais procuram utilizar discursos e atitudes consideradas racionais para com a relação médico/paciente, deixando assim de humanizar essa relação, tornando-a muitas vezes, uma relação desinteressada, com falta de comunicação, sensibilidade e afeto, o que por sua vez dificulta que o paciente consiga estabelecer uma verdadeira relação de confiança com a equipe de saúde. ${ }^{38}$

De acordo com Boff (1999) $)^{39}$, o cuidado humano não deve ser tratado como uma intervenção sobre o paciente: "a relação não é sujeito-objeto, mas sujeito-sujeito. Experimentamos os seres como sujeitos, como valores, como símbolos". E segue dizendo: "a relação do cuidado não é de domínio sobre, mas de convivência, não é pura intervenção, mas interação".

Os profissionais de saúde com frequência, já vivenciaram a morte de pacientes terminais; entretanto, a maioria nunca discutiu o assunto com tais sujeitos e tem grande dificuldade para tratar do tema com um indivíduo portador de doença terminal ${ }^{40}$. Essa dificuldade pode ser decorrente da falta de preparo desses profissionais, além do comportamento dos sujeitos durante a evolução de uma doença terminal, sendo que a educação formal sobre morte e o morrer pode diminuir a dificuldade de tratar do assunto com pacientes terminais. ${ }^{40}$

Em um estudo inicial dos cuidados do sujeito terminal em ambientes hospitalares, Glaser e Strauss $(2006)^{41}$ descobriram que os profissionais de saúde nos ambientes hospitalares evitavam a comunicação direta sobre o morrer na esperança de que o sujeito descobrisse isso por si mesmo. 


\section{Desamparo, dor e sofrimento}

Em relação à dor, constata-se que grande parte dos profissionais da saúde não sabe o que significa "dor". ${ }^{11}$ A Organização Mundial de Saúde (OMS) recomenda uma escala analgésica para alívio da dor que deve ser seguida à risca. Além disso, o profissional tem que estar aberto a medidas não-farmacológicas de analgesia, como relaxamento, meditação, suporte espiritual, hipnose e até mesmo, procedimentos que, a primeira vista, podem parecer exagerados, como bloqueio de terminação nervosa e procedimentos neurocirúrgicos. ${ }^{16}$

As bases fundamentais para o tratamento de sujeitos em Cuidados Paliativos não é encurtar nem prolongar o processo de morrer e, sim, proporcionar o alívio da dor e de outros sintomas. ${ }^{42}$ A distinção obriga a perceber que a disponibilidade de tratamento da dor em si não justifica a continuação de cuidados médicos fúteis. A continuação de tais cuidados pode simplesmente impor mais sofrimentos ao indivíduo em terminalidade de vida. ${ }^{11}$

Desta forma é possível dizer que a dor é fisiológica, enquanto o sofrimento é psicológico. O sofrimento é muito mais vasto, mais global, ou seja, uma experiência somato-psíquica. ${ }^{11}$

\section{Abordagem do termo "Cuidado Paliativo"}

A definição de cuidado paliativo é universal, apresentando uma noção de fim de vida como um processo natural para todos os seres humanos, preconizados por outros organismos internacionais, como a Organização das Nações Unidas para a Educação, Ciência e a Cultura (UNESCO), implicando na estruturação de uma rede de atenção à saúde, que é incipiente no Brasil, especialmente para as classes menos favorecidas, tendo em vista que, mesmo em planos de saúde privados, muitas vezes os cuidados paliativos não estão previstos. ${ }^{43}$

Os princípios dos cuidados paliativos podem ser assim resumidos: a) cuidar integralmente da pessoa, levando em conta os aspectos físicos, emocionais, sociais e espirituais; b) trabalhar com a família do doente, que é o núcleo fundamental de apoio; c) promover a autonomia e a dignidade do doente; d) promover o conceito ativo de terapia; e) propiciar em torno do doente uma atmosfera de respeito, apoio e comunicação; f) contar com o trabalho multidisciplinar dos profissionais. ${ }^{6}$
Muitas vezes confunde-se Cuidados Paliativos (CP) com indução da morte (eutanásia), ou com a suspensão dos tratamentos. Os Cuidados Paliativos não apresentam a morte, apenas a aceitam como parte inexorável de um processo e também não se suspende todo o tratamento, apenas os considerados fúteis, sendo que cuidar paliativamente requer, muitas vezes, um tratamento mais ativo, mais abrangente e mais complexo. ${ }^{6}$

Os cuidados paliativos são definidos pela $\mathrm{OMS}^{44}$ (1979) como: "cuidado ativo e total nas doenças que não respondem ao tratamento curativo. $\mathrm{O}$ controle da dor, de outros sintomas e os problemas psicológicos, social e espiritual são os mais importantes. A sua meta é melhorar a qualidade de vida para os pacientes e seus familiares. Muitos aspectos dos cuidados paliativos são aplicáveis mais cedo, no curso da doença, em conjunto com o tratamento. Esse acompanhamento é multiprofissional, contando com a participação de: anestesiologistas, clínicos, cirurgiões, psiquiatras, fisioterapeutas, enfermeiros, assistentes sociais e psicólogos, e muitas vezes, é necessário um apoio religioso".

Cuidados paliativos constituem uma abordagem que objetiva a melhoria na qualidade de vida do sujeito em terminalidade de vida e de seus familiares diante de uma doença que ameaça a vida, mediante a prevenção e o alívio de sofrimento, a identificação precoce, a avaliação impecável e o tratamento da dor, assim como de problemas físicos, psicológicos e espirituais. ${ }^{45}$ São compreendidos como cuidados totais e ativos que objetivam melhorar a qualidade de vida dos pacientes em fase terminal, cuja doença não responde a propostas curativas, devendo ser realizados por equipes multidisciplinares, tanto em ambiente hospitalar como nos domicílios. ${ }^{45}$

Em 2002, a OMS redefiniu cuidados paliativos como sendo "uma abordagem que aprimora a qualidade de vida, dos pacientes e famílias que enfrentam problemas associados com doenças ameaçadoras de vida, através da prevenção e alívio do sofrimento, por meios de identificação precoce, avaliação correta e tratamento da dor e outros problemas de ordem física, psicossocial e espiritual". ${ }^{6}$

Em estudo de Salamonde et al. (2006) ${ }^{42}$, os doentes terminais em fase avançada enfrentam simultaneamente vários problemas: a luta contra a doença e seus respectivos tratamentos, os problemas emocionais (raiva, depressão, desesperança, desespero, culpa, proximidade da morte) e a mudança dos planos de 
sua vida, pois deixam de lado os de longo prazo, fixando-se em metas de curto prazo.

Os cuidados paliativos são indicados nos seguintes quadros: a) enfermidade avançada, progressiva e incurável; b) falta de possibilidade razoável de resposta ao tratamento específico; c) numerosos sintomas intensos, múltiplos, multifatoriais e mutantes; d) grande impacto emocional no paciente, na família e na equipe de cuidadores, relacionado com a presença explícita ou não da morte; e) prognóstico de vida inferior a seis meses. ${ }^{6}$

Nesta direção, como apontado ao considerar a definição de cuidados paliativos da OMS, torna-se imprescindível o cultivo de três elementos fundamentais no cuidado: a compaixão, a humildade e a honestidade, em contexto e visão multidisciplinares ${ }^{46} \mathrm{O}$ trabalho com o paciente terminal requer certa maturidade que só vem com a experiência, sendo necessário examinar detalhadamente a posição adotada diante da morte e do morrer, antes de iniciar um trabalho ao lado de um paciente em fase terminal. ${ }^{47}$

\section{Consideraçø̃es Finais}

Verifica-se que, no tocante à humanização do atendimento aos sujeitos em terminalidade de vida, frente aos familiares e profissionais de saúde envolvidos, muitas iniciativas têm sido realizadas e discutidas, no entanto, ainda observam-se lacunas no que se refere ao relacionamento profissional de saúde e sujeito em fase terminal, indicando a necessidade de mais estudos na temática, a fim de permitir que os profissionais de saúde estejam melhor preparados para cuidar da vida, com humanismo e competência técnicocientífica.

\begin{abstract}
The view of health professionals opposite of life terminality is one of the most difficult situations which they have to face, because, despite best efforts, some patients will come to death. The purpose of this study is to identify and describe, through scientific literature, the aspects of promoting health and bioethics, with respect to the humanization of care in life-terminal-patients, and also how to deal with the family and health professionals involved. The methodology was based on a literature review using the search and selection of texts from databases, providing knowledge about different concepts used in humanization of health professionals regarding to life terminality and bioethical issues, in order to redress the great difficulties that health professionals have in dealing with the terminally ill and how they should be treated once the physical and emotional well being should be the focus.
\end{abstract}

Key words: Bioethics. Humanization of Assistance. Terminal Patient. Hospice Care.

\section{Referências Bibliográficas}

1. Gutierrez PL. O que é o paciente terminal. Rev Assoc Med Bras. 2001; 47:92.

2. Collet N, Rozendo CA. Humanização e trabalho na enfermagem. Rev Bras Enferm. 2003; 56:189-92.

3. Oliveira BRG, Collet N, Vieira CS. A humanização na assistência á saúde. Rev Latinoam Enferm. 2006;14:277-84.

4. Waldow VR. Cuidar expressão humanizadora da enfermagem. 1aㅡ. ed. Rio de Janeiro: Vozes. 2006; p.3-192.

5. Skaba MF. Humanização e Cuidados paliativos. Ciênc Saúde Coletiva. 2005; 10:782-4.

6. Pessini L, Bertachini L. Humanização e Cuidados Paliativos. $3^{\text {a }}$ ed. São Paulo: Loyola, Centro universitário São Camilo. 2006.319p.

7. Mota RA, Martins CGM. Papel dos profissionais de saúde na política da humanização hospitalar. Psicol Estud. 2006; 11:32330.
8. Aleksandrowicz AMC, Minayo MCS. Humanismo, liberdade e necessidade: compreensão dos hiatos cognitivos entre ciências da natureza e ética. Ciênc Saúde Coletiva. 2005; 10:513-26.

9. Bettinelli LA, Waskievicz J, Erdmann AL. Humanização do cuidado no ambiente hospitalar. In: Pessini L, Bertachini L. Humanização e Cuidados Paliativos. $3^{a}$ ed. São Paulo: Loyola, Centro universitário São Camilo. 2006. p. 87-100.

10. Deslandes SF. O projeto ético-político da humanização: conceitos, métodos e identidade. Interface Comun Saúde Educ. 2005; 9:401-3.

11. Pessini L. Humanização da dor e do sofrimento humanos na área da saúde.In: Pessini L, Bertachini L. Humanização e Cuidados Paliativos. $3^{\underline{a}}$ ed. São Paulo: Loyola, Centro universitário São Camilo. 2006. p11-30.

12. Betts J. Considerações sobre o que é humano e o que é humanizar. 2003. Disponível em URL: http://www.portal humaniza.com.br [Acesso em 21/03/2007]. 
13. Deslandes SF, Ayres JRCM. Humanização e cuidado em saúde. Ciênc Saúde Coletiva. 2005; 10:510.

14. Lepargneur H. Procurando fundamentação para humanização hospitalar. Mundo Saúde. 2003; 27:219-30.

15. Martin LM. A ética e a humanização hospitalar. In: Pessini L, Bertachini L. Humanização e Cuidados Paliativos. $3^{\underline{a}}$ ed. São Paulo: Loyola, Centro universitário São Camilo. 2006; p3150.

16. Torres WC. As perdas do paciente terminal e o luto antecipado. Psicol Argum. 2000; 19:7-12.

17. Pessini L. Distanásia: até quando investir sem agredir? Rev Bioét. 1996; 4:31-43.

18. Siqueira JE. Sobre a morte e o morrer: tecnologia ou humanismo? Rev Bioét. 2003; 49:7.

19. Saloum NH, Boemer MR. A morte no contexto hospitalar - as equipes de animação cardíaca. Rev Latinoam Enferm.1999; 7:109-20

20. Lago PM, Devictor D, Piva JP, Bergouniou J. Cuidados de final de vida em crianças: perspectiva no Brasil e no mundo. J Pediatr. 2007; 83: S109-16.

21. Bellato R, Carvalho EC. O jogo existencial e a ritualização da morte. Rev Latinoam Enferm. 2005; 13: 99-104.

22. Cohen C, Gobbetti GJ. Há autonomia para o paciente na UTI? Rev Assoc Med Bras. 2001; 47:181-2.

23. Reifsnyder J. Cuidados em fase terminal: enfermagem e os cuidados em fase terminal. In: Smeltzer SC, Bare BG. Tratado de enfermagem médico-cirúrgica. 10ª ed. Rio de Janeiro: Guanabara-Koogan, 2006; p.395-403.

24. Mauksch H. O Contexto organizacional do morrer. In: KublerRoss, E. Morte: estágio final da evolução. Trad. Ana Maria Coelho. Rio de Janeiro, Record, 1975. Apud Burlã, C. Py, L. Humanização o final da vida em pacientes idosos:manejo clínico e terminalidade. In: Pessini L, Bertachini L. Humanização e Cuidados Paliativos. $3^{a}$ ed. São Paulo: Loyola, Centro universitário São Camilo.2006.8.,p125-134.

25. Junior AS, Rolim LC, Morrone LC. O preparo do médico e a comunicação com familiares sobre a morte. Rev Assoc Med Bras. 2005; 51:11

26. Silva RCF, Hortale VA. Cuidados paliativos oncológicos, elementos para o debate de diretrizes nesta área. Cad Saúde Pública. 2006; 22:2055-66.

27. Trein, F. O homem finito ou a morte em companhia de outros homens. In: XIII Congresso Brasileiro de Geriatria e Gerontologia. SBGG,2002. Disponível em: http://www.sbgg. org.br. Apud Burlã, C. Py, L. Humanização o final da vida em pacientes idosos:manejo clínico e terminalidade. In: Pessini L, Bertachini L. Humanização e Cuidados Paliativos.3ㄹ. ed. São Paulo: Loyola, Centro universitário São Camilo. 2006, p125-134.

28. Franco, MHP. Estudos avançados sobre o luto. Campinas, Livro Pleno,2002. Apud Essilinger, I. O paciente, a equipe de saúde e o cuidador: de quem é a vida, afinal? Um estudo acerca do morrer com dignidade. In: Pessini L, Bertachini L. Humanização e Cuidados Paliativos.3ํㅡㄹ ed. São Paulo: Loyola, Centro universitário São Camilo.2006.10.,p149-163.

29. Kovács MJ. A bioética nas questões da vida e da morte. Psicol USP. 2003; 14:115-67.

30. Segre M, Cohen C. Definição de valores moral, eticidade e ética. São Paulo: Edusp. 1995; p:13-22.

31. Barchifontaine CP. Bioética : a ética da vida, da saúde e do meio ambiente. Rev Coren SP 2007: 70:4-5.
32. Torres WC. A bioética e a psicologia da saúde: reflexões sobre questões de vida e morte. Psicol Reflex Crit. 2003; 16:475-82.

33. Carvalho PRA, Rocha TS, Santo AE, Lago P. Modos de morrer na UTI pediátrica de um hospital terciário. Rev Assoc Med Bras. 2001; 47:325-31.

34. Martin LM. A ética e a humanização hospitalar. In: Pessini L, Bertachini L. Humanização e Cuidados Paliativos. $3^{a}$ ed. São Paulo: Loyola, Centro universitário São Camilo.2006.2.,p3150.

35. Hoffmam L. A morte na infância e sua representação para o médico - reflexões sobre a prática pediátrica em diferentes contextos. Cad Saúde Pública. 1993; 19(3):364-74.

36. Zoboli E. Bioética: um instrumento pela vida. Rev Coren SP 2007; 70:20-5

37. Catholic Health Association, op.cit.,28-39. Apud Pessini L. Humanização da dor e do sofrimento humanos na área da saúde.In: Pessini L, Bertachini L. Humanização e Cuidados Paliativos. $3^{\mathrm{a}}$ ed. São Paulo: Loyola, Centro Universitário São Camilo.2006. p11-30.

38. Gambatto R, Carli FC, Guarienti RF, Silva ALP, Prado AB. Mecanismos de defesa utilizados por profissionais de saúde no tratamento de câncer de mama. Psicol Am Lat. 2006. Disponível em: <http://pepsic.bvs-psi.org.br/scielo . ph p ? script =sci_arttext\&pid=S $1870-$ $350 \times 2006000200005 \&$ lng $=p t \& n r m=i s o>$.ISSN 1870-350X. [Acesso em 28/03/2007].

39. Boff, L. Saber cuidar. Petrópolis. Vozes.1999 Apud Bettinelli, LA. Waskievicz, J. Erdmann, AL. Humanização do cuidado no ambiente hospitalar. In: Pessini L, Bertachini L. Humanização e Cuidados Paliativos.3a ed. São Paulo: Loyola, Centro universitário São Camilo.2006. p87-100

40. Viana A, Peccelli H. O estudante, o médico e o professor perante a morte e o paciente terminal. Rev Assoc Med Bras. 1998; 44:21-7.

41. Glaser BG, Strauss AL.1965. Awareness of dying. Chicago: Aldine.apud Reifsnyder J. Cuidados em fase terminal: enfermagem e os cuidados em fase terminal. In: Smeltzer SC, Bare BG. Tratado de enfermagem médico-cirúrgica. 10aㅡ ed. Rio de Janeiro: Guanabara-Koogan, 2006; p.395-403.

42. Salamonde GLF, Verçosa N, Barrucand L, Costa AFC. Análise crítica e terapêutica dos pacientes oncológicos atendidos no programa de dor e cuidados paliativos do hospital universitário Clemente Fraga Filho no ano de 2003. Rev Bras Anestesiol. 2006; 56: 602-18.

43. Simoni M, Santos ML. Considerações sobre cuidados paliativos e trabalho hospitalar: uma abordagem plural sobre o processo de trabalho de enfermagem. Psicol USP. 2003; 14:169-94.

44. Melo AGC. Cuidados paliativos: histórico e filosofia. 2004 Disponível em URL: http://www.oncoguia.com.br/dor [Acesso em 23/03/2007].

45. Fortes PAC. A prevenção da distanásia nas legislações brasileiras e francesas. Rev Assoc Med Bras. 2007; 53:195-7.

46. Mccoughlan, M. A necessidade de cuidados paliativos. In: Pessini L, Bertachini L. Humanização e Cuidados Paliativos. $3^{\text {a }}$ ed. São Paulo: Loyola, Centro universitário São Camilo.2006. p167-180.

47. Kubler-Ross E. Sobre a morte e o morrer. Terapia com doentes em fase terminal. 8 ${ }^{\underline{a}}$ ed. São Paulo: Martins Fontes. 1998. p.275-282. 